\title{
Macroscopic Mechanical Characterization of SMAs Fiber-Reinforced Hybrid Composite Under Uniaxial Loading
}

Hongshuai Lei, Zhenqing Wang, Liyong Tong, and Xiaojun Tang

(Submitted January 21, 2013; in revised form March 30, 2013; published online May 21, 2013)

\begin{abstract}
This paper presents an experimental and theoretical investigation on the macroscopic mechanical behavior of shape memory alloys (SMAs) fiber-reinforced glass/resin composite subject to uniaxial loading at ambient temperature. A series of unidirectional SMAs reinforced composite laminates is fabricated through vacuum-assisted resin injection. Scanning electron microscopy is conducted to evaluate the interfacial cohesive quality between SMAs fiber and matrix. A theoretical model is proposed based on the SMAs phase transformation model and rule of mixture. Uniaxial tensile tests are performed to study the effects of weak interface and SMAs fiber volume fraction on the effective modulus of composite. Failure morphology of composite is discussed based on the observation using digital HF microscope. Due to the effects of phase transformation and weak interface, the overall stiffness of SMAs composite at the second stage is on average $10 \%$ lower than theoretical results. The rupture elongation of experimental result is approximately $13 \%$ higher than theoretical result. The local interfacial debonding between SMAs fiber and glass/resin matrix is the main failure mode.
\end{abstract}

Keywords composite, mechanical behavior, shape memory alloys, weak interface

\section{Introduction}

Shape memory alloys (SMAs) are gaining interest in the aerospace, automotive, civil engineering, and medical industries due to their unique characteristics, such as shape memory effect (SME), super-elasticity (SE), and high damping capacity. To design an intelligent composite or smart structure, the SMAs fiber are usually filled or embedded into host materials, for instance the epoxy resin, metal matrix, and hybrid laminate plate (Ref 1-3). The SME and SE properties can effectively reduce the local stress concentration in composite as well as increase fracture toughness. However, the enhancement and toughness effects are often limited by the weak interfacial cohesive between SMAs fiber and matrix (Ref 4). Thus, it is essential to investigate the macroscopic mechanical behavior of SMAs fiber-reinforced composite.

Many researchers have investigated the macroscopic mechanical response of SMAs reinforced composite subjected to various loading conditions through experimental tests, and

Hongshuai Lei, College of Aerospace and Civil Engineering, Harbin Engineering University, Harbin, China; and school of Aerospace, Mechanical and Mechatronic Engineering, University of Sydney, Sydney, NSW 2006, Australia; Zhenqing Wang and Xiaojun Tang, College of Aerospace and Civil Engineering, Harbin Engineering University, Harbin, China; and Liyong Tong, School of Aerospace, Mechanical and Mechatronic Engineering, University of Sydney, Sydney, NSW 2006, Australia. Contact e-mail: leihongshuai@hrbeu.edu.cn. found that the embedment of SMAs could effectively improve the overall structural response of host materials in terms of stiffness and strength (Ref 5-11). Fathollah et al. (Ref 5) assumed the bond between the SMAs wires and matrix was intact, and evaluated the mechanical properties of SMAs hybrid composite plate based on a standard rule of mixtures (ROM) micromechanics relation. Raghavan et al. (Ref 6) evaluated the potential of super-elastic SMAs fibers to enhance the damping capacity and toughness of a thermoset polymer matrix, and they confirmed that the mechanical properties of polymer matrix were significantly improved due to the reinforcement with super-elastic SMAs fibers by experimental tests, such as damping, strength, and impact property. Zhou and Lloyd (Ref 7) introduced a method to fabricated SMAs hybrid composite, and characterized the bending behavior of SMAs reinforced E-glass/epoxy beams through experiment. It was observed that the end deflections of beam was up to $41 \mathrm{~mm}$ due to the derived SMAs wire. Aurrekoetxea et al. (Ref 8) investigated the effect of super-elastic SMAs wire on the low-velocity impact properties of carbon fiber-reinforced composite through instrumented impact tests. They suggested that the contribution of the SMA wires to the higher impact performance of the hybrid composite was attributed to their energy absorbing capability, and the high reversible force that acted as a healing force. Zhang et al. (Ref 9) investigated the flexural rigidity of short-SMA-fiber-reinforced epoxy composite, and performed three-point bending test at a constant temperature. The effects of weight fraction on flexural rigidity and storage modulus were discussed. A model for the laminated plates with SMA fillers was presented to predict the dynamic mechanical properties based on the Halpin-Tsai theory. Kang and Kim (Ref 10) investigated the damage behavior and residual properties of SMAs composite laminates subjected to low-velocity impact at low temperatures. It was found that the 


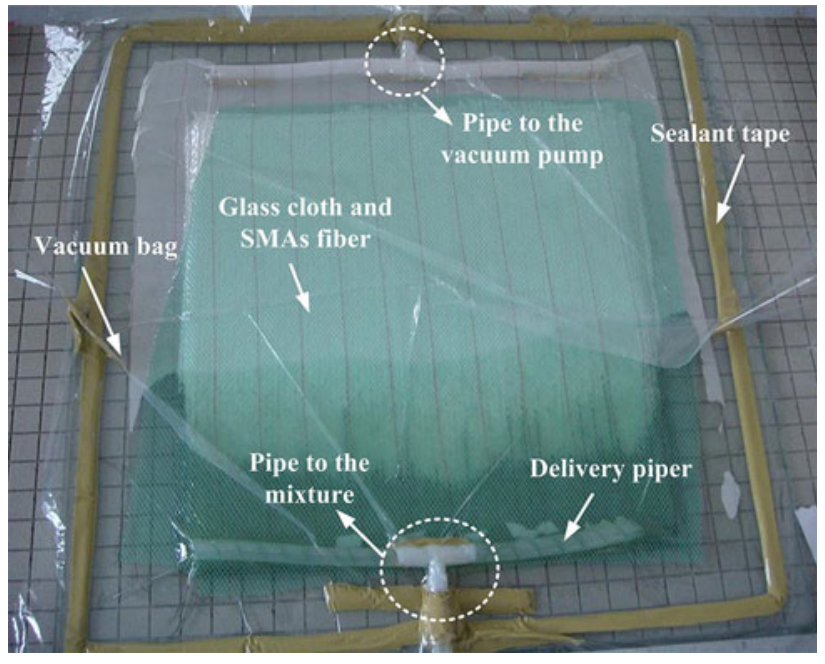

Fig. 1 Illustration of the fabrication of resin/glass SMAs hybrid composite

influence of temperature on the impact damage behavior and strength threshold energy of SMAs laminates was slightly relative to base laminate. Pappadà et al. (Ref 11) investigated the mechanical and vibration properties of super-elastic SMAs fiber-reinforced glass/resin laminate plate. The experimental results shown the impact strength of hybrid composite was improved, while the flexural mechanical properties were decreased due to hybridization. It should be mentioned that there was a common phenomenon in the experiments. The interfacial debonding failure usually occurred between SMAs fiber and matrix, which limited the enhancement effect of SMAs fiber. In the previous studies $(\operatorname{Ref} 4,12)$, the authors have investigated the effect of interface between SMAs fiber and matrix on the overall mechanical behaviors of composites by experimental tests and finite element analysis.

Recently, several theoretical and finite element models have been proposed to evaluate the effect of SMAs fiber when the composite structures subjected to various loading conditions (Ref 13-20). For instance, Tawfik et al. (Ref 13) utilized a nonlinear finite element model to study the effectiveness of a SMA-embedded isotropic panel on the critical buckling temperature, postbuckling deflection, free vibration, and flutter boundary. Lu et al. (Ref 14) developed an 1D constitutive relation of the SMAs lamina using the method of micromechanics. They assumed that the SMAs fiber was embedded into the neutral plan of layer, and discussed the bending behavior of SMAs-reinforced composite beam under various temperatures. Kuo et al. (Ref 15) studied the buckling of SMAs reinforced composite laminate using the active strain energy tuning and active property tuning methods. The effects of SMAs fiber volume fraction and prestrain level on the overall stiffness and critical buckling load of composite were discussed. They found that the enhancement was considerable when the SMAs fibers were concentrated in the center of the plate. John and Hariri (Ref 16) investigated the effect of SMAs actuation on the dynamic response of polymeric composite. They presented an analytical solution for SMAs composite beam using RayleighRitz method, and demonstrated the alteration of dynamic structural properties using SMAs was possible, even though the changes observed in experiment were rather small. Kim et al. (Ref 17) investigated the damage resistance of composite plates

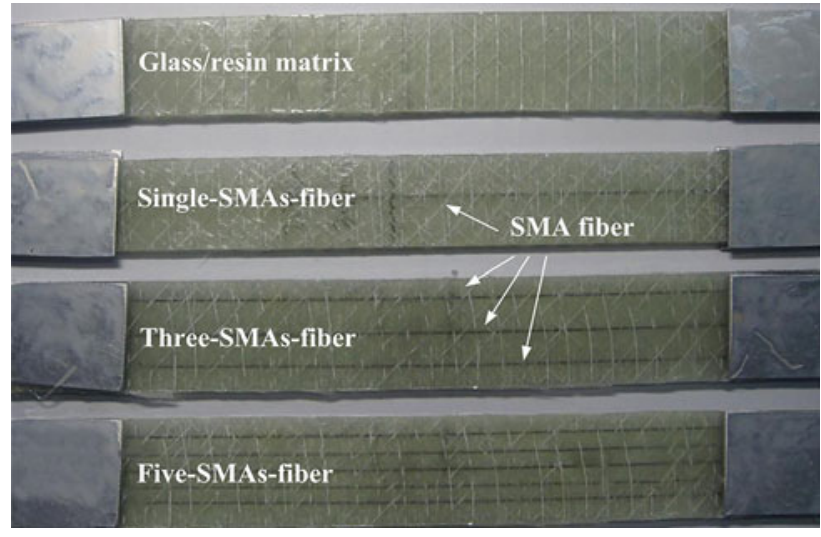

Fig. 2 Typical specimens of SMAs hybrid composite with single fiber, three fibers, and five fibers
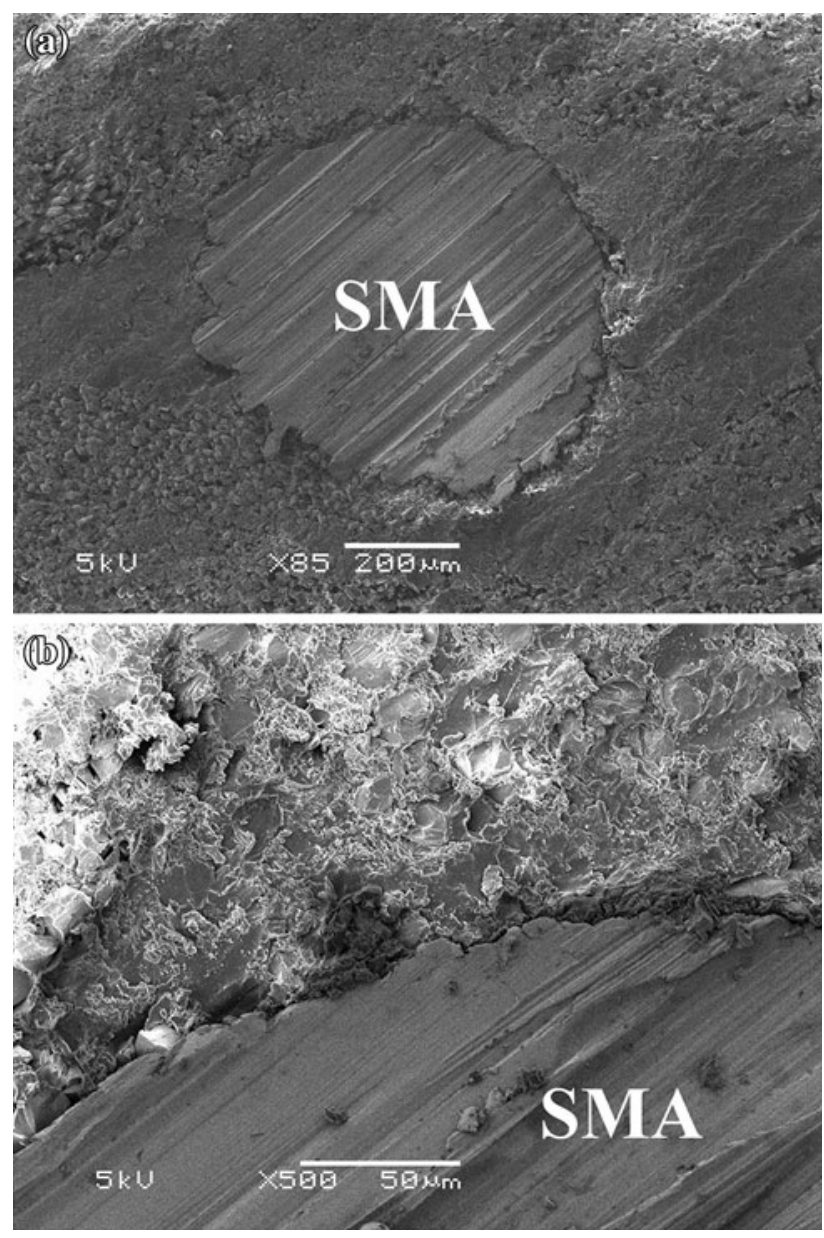

Fig. 3 SEM micrographs of showing interfacial bond between SMAs fiber and matrix material

embedded with SMA thin films under low velocity impact via finite element simulation, and they found that embedding SMA strips on the composite plate was effective to increase the impact resistance of the composite plates. Actually, these theoretical models were developed based on the assumption of perfect interface between wires and matrix, resulting in strain compatibility across the interface. 


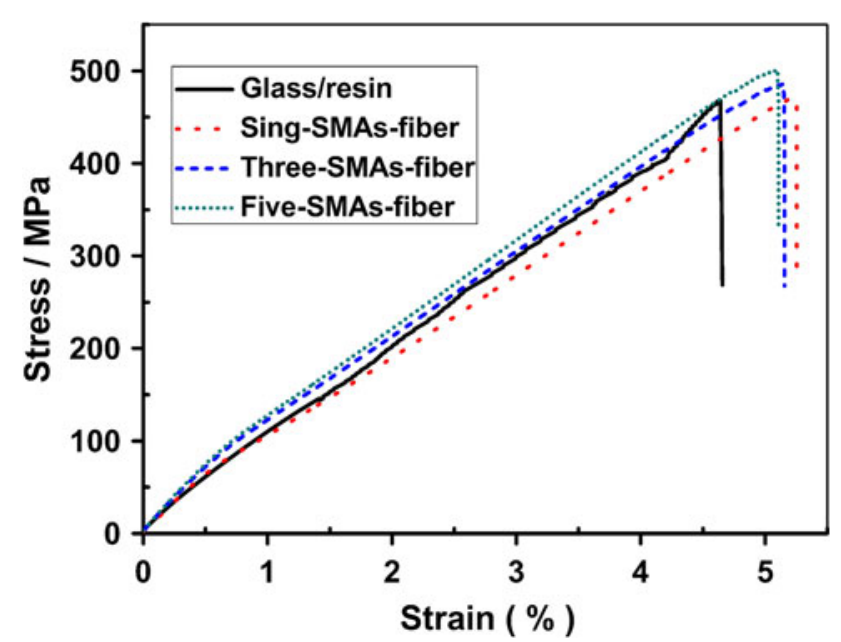

Fig. 4 Stress-strain curves of glass/resin matrix and SMAs composite at ambient temperature

The objective of the present work was to investigate the macroscopic mechanical behavior of SMAs fiber-reinforced composite through experiment and theoretical analysis. A series of unidirectional SMAs fiber-reinforced glass/resin composite laminate was fabricated through vacuum-assisted resin injection (VARI). Scanning electron microscopy (SEM) and uniaxial tensile test were performed to evaluate the interfacial cohesive quality and overall effective modulus of composite. A theoretical model was proposed based on SMAs phase transformation model and ROM. The failure morphology was observed using digital HF microscope.

\section{Experimental Details}

\subsection{Materials}

The SMAs fiber in the present study was equal-atomic super-elastic Ni-Ti alloy wire, and the diameter was $0.5 \mathrm{~mm}$. The host material was Unsaturated Polyester Resin 189 which could be cured at ambient temperature. Dimethylaniline and methyl ethyl ketone peroxide were selected as accelerating agent and hardening agent, respectively. The resin was mixed with accelerator and hardener at the mass ratio $1: 1 \%: 0.25 \%$. The reinforced material was unidirectional glass fiber cloth, and the density was $300 \mathrm{~g} / \mathrm{m}^{2}$.

\subsection{Manufacturing}

To characterize the mechanical behavior of SMAs hybrid composite, a series of SMA/glass/resin laminates was fabricated by VARI. The fabricated process and setup was shown in Fig. 1. As seen, 16-ply glass cloth was stacked as the antisymmetric laying. The SMAs fiber was placed on the middle plane of laminate, and parallel to each other. A delivery pipe was located at the entrance to ensure the resin mixture flowing uniformly. The laminate was placed on a glass tool, and covered with the peel ply, silk ply, and plastic bag. After resin infusion, curing at ambient temperature and the vacuum level of 600 mbar was performed for $24 \mathrm{~h}$. It should be mentioned that the draw speed of resin mixture should be low enough to ensure the resin uniform distribution in laminate. Additionally, to

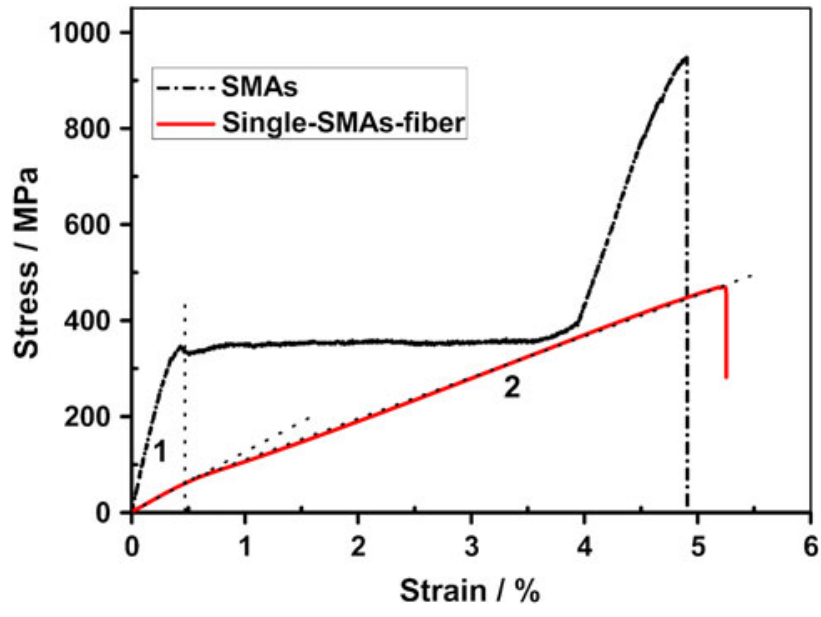

Fig. 5 Stress-strain curves of SMAs fiber and single-SMAs fiber composite at ambient temperature

facilitate good adhesion between wires and resin of the host material, the wire's surface was polished by sanding, thoroughly cleaned by acetone and purged the stain by ultrasonic cleaner before being embedded in host material.

\subsection{Interface Observation}

It has been confirmed that due to the discrepancy in material compatibility, usually there were many weak interfaces between SMAs fiber and hybrid matrix (Ref 4). Thus, to evaluate the quality of interfacial adhesion between SMAs fiber and matrix, SEM was conducted on the hybrid composite specimens in the present study.

\subsection{Tensile Test}

Four types of specimens (as seen in Fig. 2) were cut from the square panels using a diamond saw blade cutting machine along the direction of SMAs fiber axial, including glass/resin matrix, single-SMAs-, three-SMAs-, and five-SMAs-fiber hybrid plates. The specimen dimension was $200 \times 26 \times$ $3.5 \mathrm{~mm}$, and the calibrating length was $100 \mathrm{~mm}$. Uniaxial tensile tests were performed at ambient temperature, and four specimens per type. A constant strain-controlled loading was selected, and the cross-head speed was $2 \mathrm{~mm} / \mathrm{min}$.

\section{Theoretical Model}

\subsection{Thermo-mechanical Model of SMAs Fiber}

As known, several constitutive models have been developed to predict the thermo-mechanical behavior of SMAs, such as Tanaka model (Ref 21), Liang-Rogers model (Ref 22), Boyd-Lagoudas model (Ref 23), and Brinson model (Ref 24). In the present paper, the Brinson's model will be utilized. It should be noted that the martensite volume fraction (denoted as $\xi$ ) in this model was divided into two parts: stress-induced $\left(\xi_{\mathrm{s}}\right)$ and temperatureinduced $\left(\xi_{\mathrm{T}}\right)$. The basic equation and relation for super-elastic SMAs model are summarized in this section as follows. 
Table 1 Material parameters for calculation obtained from experiment

\begin{tabular}{|c|c|c|c|c|c|c|c|c|}
\hline \multirow[t]{4}{*}{ SMAs } & $E_{\mathrm{a}}$ & $94.4 \mathrm{GPa}$ & $C_{\mathrm{a}}$ & 7.5 & $A_{\mathrm{s}}$ & $279.5 \mathrm{~K}$ & $\sigma_{\mathrm{s}}^{\mathrm{cr}}$ & $365.9 \mathrm{MPa}$ \\
\hline & $E_{\mathrm{m}}$ & $58.4 \mathrm{GPa}$ & $C_{\mathrm{m}}$ & 9.3 & $A_{\mathrm{f}}$ & $287.1 \mathrm{~K}$ & $\sigma_{\mathrm{f}}^{\mathrm{cr}}$ & $412.7 \mathrm{MPa}$ \\
\hline & $\varepsilon_{\mathrm{L}}$ & $3.37 \%$ & $a_{\mathrm{a}}$ & $0.413 \mathrm{~K}^{-1}$ & $M_{\mathrm{s}}$ & $280.7 \mathrm{~K}$ & $\sigma_{f}^{u}$ & $950.1 \mathrm{MPa}$ \\
\hline & $\varepsilon_{\max }^{\mathrm{f}}$ & $4.91 \%$ & $a_{\mathrm{m}}$ & $0.135 \mathrm{~K}^{-1}$ & $M_{\mathrm{f}}$ & $257.4 \mathrm{~K}$ & $V_{\mathrm{f}}$ & 0.27 \\
\hline Glass/resin & $\begin{array}{l}\max \\
E_{11} \\
E_{22}\end{array}$ & $\begin{array}{l}9.95 \mathrm{GPa} \\
3.2 \mathrm{GPa}\end{array}$ & $V_{\mathrm{m}}$ & 0.2 & $\varepsilon_{\max }^{\mathrm{m}}$ & $4.64 \%$ & $\sigma_{\mathrm{m}}^{\mathrm{u}}$ & $468.3 \mathrm{MPa}$ \\
\hline
\end{tabular}

The increment constitutive equation is expressed as

$\sigma-\sigma_{0}=E(\xi) \varepsilon-E\left(\xi_{0}\right) \varepsilon_{0}+\Omega(\xi) \xi_{s}-\Omega\left(\xi_{0}\right) \xi_{0}+\Theta\left(T-T_{0}\right)$

where $E, \Omega$, and $\Theta$ denote the elastic modulus, phase transformation modulus, and thermal modulus, respectively. $\sigma, \varepsilon$, and $T$ are the stress, total strain, and temperature, respectively. The superscript 0 refers to the initial reference state.

Due to the difference in mechanical properties between austenite phase and martensite phase, the modules of SMAs are assumed as a linear function of martensite volume fraction and expressed as

$$
\left\{\begin{array}{l}
E(\xi)=E_{\mathrm{a}}+\left(E_{\mathrm{m}}-E_{\mathrm{a}}\right) \xi \\
\Omega(\xi)=-\varepsilon_{\mathrm{L}} E(\xi) \\
\Theta(\xi)=E(\xi)\left(\alpha_{\mathrm{a}}+\left(\alpha_{\mathrm{m}}-\alpha_{\mathrm{a}}\right) \xi\right)
\end{array}\right.
$$

where $E_{\mathrm{a}}$ and $\alpha_{\mathrm{a}}$ are the elastic modulus and thermal expansion coefficient in austenite phase; similarly, $E_{\mathrm{m}}$ and $\alpha_{\mathrm{m}}$ refer to the modulus in martensite phase. $\varepsilon_{\mathrm{L}}$ is a material constant defined as the maximum memory strain which can be obtained through uniaxial tensile test.

In addition, the evolution of martensite volume fraction containing of two processes: conversion of austenite phase into martensite phase and conversion of martensite phase into austenite phase. The evolution equations are expressed as

From austenite phase into martensite phase:

$\left\{\begin{array}{l}\sigma_{\mathrm{s}}^{\mathrm{cr}}+C_{\mathrm{m}}\left(T-M_{\mathrm{s}}\right)<\sigma<\sigma_{\mathrm{f}}^{\mathrm{cr}}+C_{\mathrm{m}}\left(T-M_{\mathrm{s}}\right) \quad\left(T \geq M_{\mathrm{s}}\right) \\ \xi=\frac{1-\xi_{0}}{2} \cos \left\{\frac{\pi}{\sigma_{\mathrm{s}}^{\mathrm{cr}}-\sigma_{\mathrm{f}}^{\mathrm{cr}}}\left[\sigma-\sigma_{\mathrm{f}}^{\mathrm{cr}}-C_{\mathrm{m}}\left(T-M_{\mathrm{s}}\right)\right]\right\}+\frac{1+\xi_{0}}{2}\end{array}\right.$

$\left\{\begin{array}{l}\sigma_{\mathrm{s}}^{\mathrm{cr}}<\sigma<\sigma_{\mathrm{f}}^{\mathrm{cr}}\left(T<M_{\mathrm{s}}\right) \\ \xi=\frac{1-\xi_{0}}{2} \cos \left[\frac{\pi}{\sigma_{\mathrm{s}}^{\mathrm{cr}}-\sigma_{\mathrm{f}}^{\mathrm{cr}}}\left(\sigma-\sigma_{\mathrm{f}}^{\mathrm{cr}}\right)\right]+\frac{1+\xi_{0}}{2} .\end{array}\right.$

From martensite phase into austenite phase:

$\left\{\begin{array}{l}C_{\mathrm{a}}\left(T-A_{\mathrm{f}}\right)<\sigma<C_{\mathrm{a}}\left(T-A_{\mathrm{s}}\right) \quad\left(T>A_{\mathrm{s}}\right) \\ \xi=\frac{\xi_{0}}{2}\left\{\cos \left[a_{\mathrm{a}}\left(T-A_{\mathrm{s}}-\frac{\sigma}{C_{\mathrm{a}}}\right)\right]+1\right\}\end{array}\right.$

where $\sigma_{\mathrm{s}}^{\mathrm{cr}}$ and $\sigma_{\mathrm{f}}^{\mathrm{cr}}$ are the critical stress at both start and finish of transformation. $C_{\mathrm{m}}$ and $C_{\mathrm{a}}$ are the material constants describing the relationship between temperature and critical transformation stress. $M_{\mathrm{s}}, M_{\mathrm{f}}, A_{\mathrm{s}}$, and $A_{\mathrm{f}}$ are the phase transformation start and finish temperature in austenite and martensite, respectively. $a_{\mathrm{a}}$ is a material constant, and equal to $\pi /\left(A_{\mathrm{f}}-A_{\mathrm{s}}\right)$.

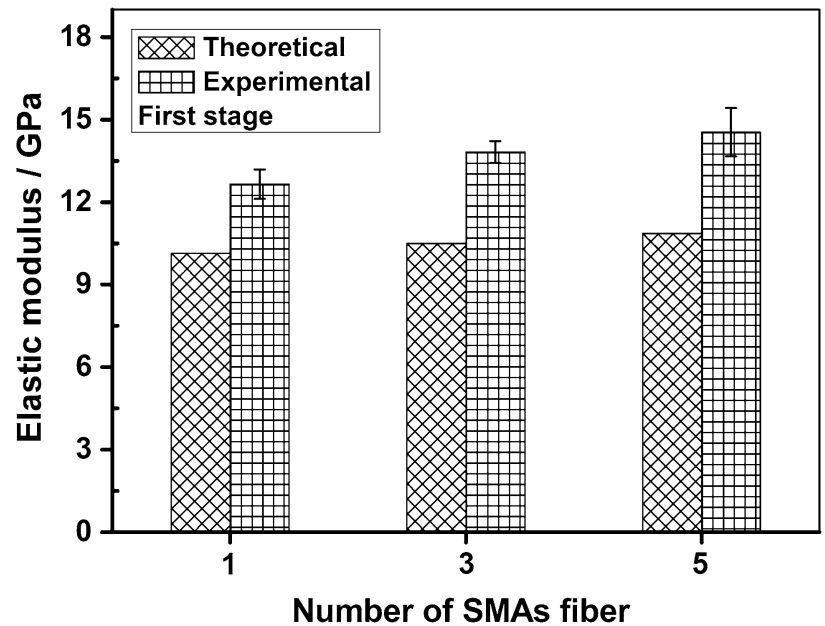

(a) First stage

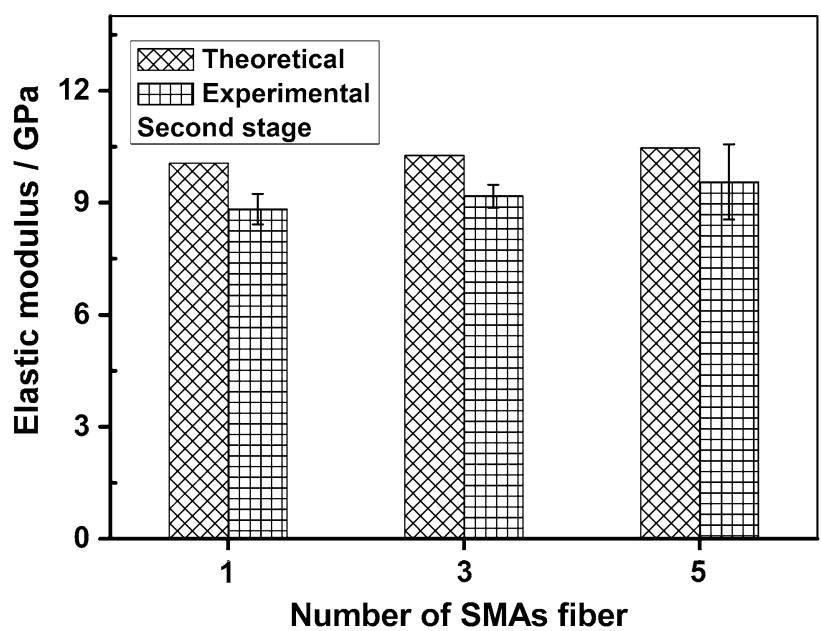

(b) Second stage

Fig. 6 Comparison of macroscopic elastic modulus between theoretical and experimental results

\subsection{Effective Modulus of SMAs Composite}

It has been demonstrated that the macroscopic mechanical response of composite will be significantly changed due to the embedment of SMAs fiber. To estimate the effective modulus of reinforced composite, the ROM has been commonly used which can be derived from strain energy theory. Fathollah et al. (Ref 5) suggested an ROM equation for the SMAs hybrid composites which is based on the assumption of perfect interface between fiber and matrix as 
Table 2 Comparison of experimental results and theoretical results of effective modulus of SMAs composite

\begin{tabular}{|c|c|c|c|c|c|}
\hline \multirow[b]{2}{*}{ Specimens } & \multirow[b]{2}{*}{ Data category } & \multicolumn{2}{|c|}{ Young's modulus } & \multirow[b]{2}{*}{$\sigma_{\mathrm{c}}^{\mathrm{u}}$} & \multirow[b]{2}{*}{$\varepsilon_{\mathrm{c}}^{\mathrm{u}}, \%$} \\
\hline & & First stage & Second stage & & \\
\hline \multirow[t]{3}{*}{ Single-SMAs-fiber $\left(V_{\mathrm{f}}=0.22 \%\right)$} & Experimental & $12.65 \mathrm{GPa}$ & $8.83 \mathrm{GPa}$ & $469.1 \mathrm{MPa}$ & 5.25 \\
\hline & Theoretical & $10.14 \mathrm{GPa}$ & $10.06 \mathrm{GPa}$ & $469.2 \mathrm{MPa}$ & 4.67 \\
\hline & Enhancement & $24.75 \%$ & $-12.23 \%$ & $-0.02 \%$ & 12.42 \\
\hline \multirow[t]{3}{*}{ Three-SMAs-fiber $\left(V_{\mathrm{f}}=0.65 \%\right)$} & Experimental & $13.82 \mathrm{GPa}$ & $9.18 \mathrm{GPa}$ & $486.0 \mathrm{MPa}$ & 5.16 \\
\hline & Theoretical & $10.5 \mathrm{GPa}$ & $10.26 \mathrm{GPa}$ & $470.8 \mathrm{MPa}$ & 4.6 \\
\hline & Enhancement & $31.62 \%$ & $-10.53 \%$ & $3.23 \%$ & 12.17 \\
\hline \multirow{3}{*}{ Five-SMAs-fiber $\left(V_{\mathrm{f}}=1.08 \%\right)$} & Experimental & $14.54 \mathrm{GPa}$ & $9.56 \mathrm{GPa}$ & $501.2 \mathrm{MPa}$ & 5.10 \\
\hline & Theoretical & $10.86 \mathrm{GPa}$ & $10.47 \mathrm{GPa}$ & $472.5 \mathrm{MPa}$ & 4.51 \\
\hline & Enhancement & $33.89 \%$ & $-8.69 \%$ & $6.07 \%$ & 13.08 \\
\hline
\end{tabular}

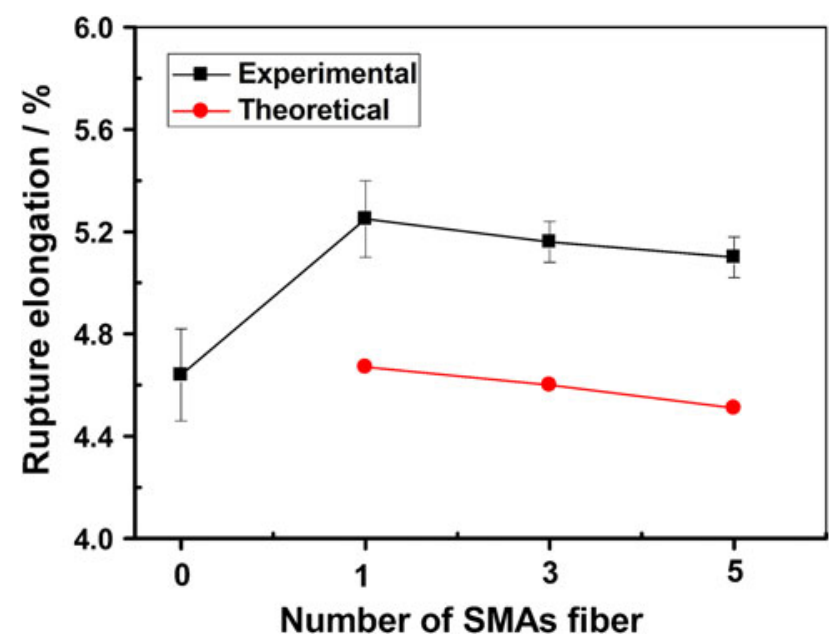

Fig. 7 Comparison of macroscopic rupture elongation between theoretical and experimental results

$E_{\mathrm{c}}=V_{\mathrm{f}} E_{\mathrm{f}}+V_{\mathrm{m}} E_{\mathrm{m}}$

$E_{\mathrm{c}}, E_{\mathrm{f}}$, and $E_{\mathrm{m}}$ are the elastic modulus of composite, SMAs fiber, and glass/resin matrix, respectively. $V_{\mathrm{f}}$ and $V_{\mathrm{m}}$ are respectively, the volume fraction of SMAs fiber and matrix, and they should satisfy the relation of $V_{\mathrm{f}}+V_{\mathrm{m}}=1$.

Substituting Eq 2 into Eq 6, the elastic modulus of SMAs composite can be obtained and expressed as follows relating to martensite volume fraction,

$E_{\mathrm{c}}=V_{\mathrm{f}}\left(E_{\mathrm{f}}^{\mathrm{a}}+\left(E_{\mathrm{f}}^{\mathrm{m}}-E_{\mathrm{f}}^{\mathrm{a}}\right) \xi\right)+V_{\mathrm{m}} E_{\mathrm{m}}$.

The ultimate strength $\sigma_{\mathrm{c}}^{\mathrm{u}}$ of composite is given by

$\sigma_{\mathrm{c}}^{\mathrm{u}}=V_{\mathrm{f}} \sigma_{\mathrm{f}}^{\mathrm{u}}\left(\varepsilon_{\max }^{\mathrm{m}}\right)+V_{\mathrm{m}} \sigma_{\mathrm{m}}^{\mathrm{u}}\left(\varepsilon_{\max }^{\mathrm{f}}\right)$

where $\sigma_{\mathrm{f}}^{\mathrm{u}}$ and $\sigma_{\mathrm{m}}^{\mathrm{u}}$ are the ultimate strength of fiber and matrix, respectively. $\sigma_{\mathrm{f}}^{\mathrm{u}}\left(\varepsilon_{\max }^{\mathrm{m}}\right)$ denotes the strength of fiber corresponding to the macroscopic strain of fiber reach to $\varepsilon_{\max }^{\mathrm{m}}$. This equation means the ultimate strength of composite is mainly depending to the weak material.

The rupture elongation of SMAs fiber composite can be derived according to the Hooke's law, Eq 2-5, 7 and 8. It should be mentioned that the mechanical behavior of SMAs hybrid composite was a bilinear relation, which has been confirmed in experiment.

$$
\varepsilon_{\mathrm{c}}^{\mathrm{u}}=\frac{V_{\mathrm{f}} \sigma_{\mathrm{f}}^{\mathrm{u}}\left(\varepsilon_{\max }^{\mathrm{m}}\right)+V_{\mathrm{m}} \sigma_{\mathrm{m}}^{\mathrm{u}}\left(\varepsilon_{\mathrm{max}}^{\mathrm{f}}\right)}{V_{\mathrm{f}}\left(E_{\mathrm{f}}^{\mathrm{a}}+\left(E_{\mathrm{f}}^{\mathrm{m}}-E_{\mathrm{f}}^{\mathrm{a}}\right) \xi\right)+V_{\mathrm{m}} E_{\mathrm{m}}} .
$$

\section{Results and Discussion}

\subsection{Interface Analysis}

The interfacial cohesive quality between SMAs fiber and matrix is shown in Fig. 3. Since the SMAs diameter is about two times than the nominal ply thickness, thus the localized waviness in the micrograph can be observed in the region around SMAs fiber as shown in Fig. 3(a). With the increase of vacuum level, two adjacent glass/resin layers gradually squeeze SMAs fiber, and resin is slowly filled into the surrounding region.

Figure 3(b) is the partial enlargement micrograph to evaluate the interfacial adhesion quality between SMAs fiber and host material. As seen, the dark region is SMAs fiber, while the bright region is host material. It can be clearly observed that a small gap surrounding the SMAs fiber which has been defined as "weak interface" in literature (Ref 4). During the loading process, the ability of composite to effectively support and transmit loading would be limited by the weak interface. Note that the phase transformation behavior and mechanical properties of SMAs fiber would be changed due to the hard constrained of matrix, which has been demonstrated by Jiang et al. (Ref 25) using differential scanning calorimeter and thermal dilatation analyzer. However, the effect of constrain was not taken into account in the present study.

\subsection{Bilinear Behavior of SMAs Composite}

The macroscopic stress-strain curves of glass/resin matrix and SMAs fiber-reinforced composite are shown in Fig. 4 when subjected to uniaxial loading at ambient temperature. It can be found that the mechanical behavior of glass/resin matrix appears to be an approximately linear relationship at the initial stage of strain, and then it performs a transient plastic yielding. The elastic modulus of glass/resin matrix is $9.95 \mathrm{GPa}$, and the ultimate strength is about $468.3 \mathrm{MPa}$. In addition, it can be found that the effect of SMAs fiber on the mechanical response is significant through observing the curves of composite. An approximately bilinear mechanical behavior during the loading process is exhibited. The overall elastic modulus, ultimate 
strength, and rupture elongation of composite was gradually changed with the embedment of SMAs fiber.

To clarify the mechanism of SMAs fiber, the comparison stress-strain curves between glass/resin matrix and singleSMAs fiber composite was shown in Fig. 5. As seen, it can be found that the unique bilinear behavior of composite is related to the phase transformation of SMAs fiber. In present study, the stage is separated into two parts: first stage is the macroscopic strain from zero to the starting point of phase transformation, and the subsequent stage is defined as the second stage. At the first stage, from $\varepsilon=0$ to $\varepsilon=0.42 \%$, the SMAs fiber and glass/ resin matrix are all at the linear elastic state. When the strain in excess of $0.42 \%$, the interior stress of SMAs fiber will increase to the critical phase transformation stress, and then it will gradually transform from austenite phase to martensite phase. Owing to the change of mechanical properties of SMAs fiber, the overall behavior of composite is changed. Thus, we define the effect process of phase transformation as the second stage. Fathollah et al. (Ref 5) investigated the mechanical behavior of hybrid composite plate subject to static loading, and defined a bilinear macroscopic relation which were coincident with the experimental results in this paper.

\subsection{Effective Modulus of SMAs Composite}

To estimate the effects of SMAs fiber and weak interface on the macroscopic response of SMAs composite, the effective modulus of SMAs composite, including elastic modulus, rupture elongation, and ultimate strength, are compared between experimental results and theoretical results. The material parameters of SMAs fiber and glass/resin matrix for theoretical calculation obtained from experimental tests are listed in Table 1. For SMAs fiber, the elastic modulus of pure martensite and austenite phase are, respectively, 58.4 and 94.4 GPa. The ultimate strength and rupture elongation are about $950.1 \mathrm{MPa}$ and $4.91 \%$, respectively. The critical phase transformation stresses at ambient temperature are 365.9, 412.7, 98.83, and 61.51 $\mathrm{MPa}$, respectively.

The elastic modulus of SMAs composite with different number of embedded SMAs fiber at the two stages are calculated by Eq 3-5 and 7. For the single-SMAs-, three-SMAs-, and five-SMAs-fiber composite, the volume fraction of SMAs fiber is $0.22,0.65$, and $1.08 \%$, respectively. Figure 6 shows the comparison of overall elastic modulus between theoretical results and experimental results. It is obvious that the elastic modulus of composite are remarkably increased to $12.65,13.82$, and $14.54 \mathrm{GPa}$ at the first stage as shown in Fig. 6(a). In contrast to theoretical results, the values are enhanced by approximately $30 \%$. It indicates the bonding interface between SMAs fiber and matrix is effective and could effectively transfer the external loading. For the second stage as shown in Fig. 6(b), the elastic modulus values of composite, respectively, are $8.83,9.18$, and $9.56 \mathrm{GPa}$ which are lower than theoretical results up to $12.23 \%$, especially for the single-SMAsfiber composite. It should be noted that the overall stiffness of composite is slightly lower than glass/resin matrix. This is mainly due to that some micro-cracks are generated in local region of hybrid composite with the increase of strain, which will result in the degradation of stiffness. The phenomenon is attributed to the presence of weak interface which has been observed in experiment. Actually, the overall stiffness of composite is gradually increased with the volume fraction of SMAs fiber. As seen, for the first stage, it is increased from 12.65 to $14.54 \mathrm{GPa}$, enhanced by $14.94 \%$; for the second stage, it is enhanced by $8.27 \%$ from 8.83 to $9.56 \mathrm{GPa}$.

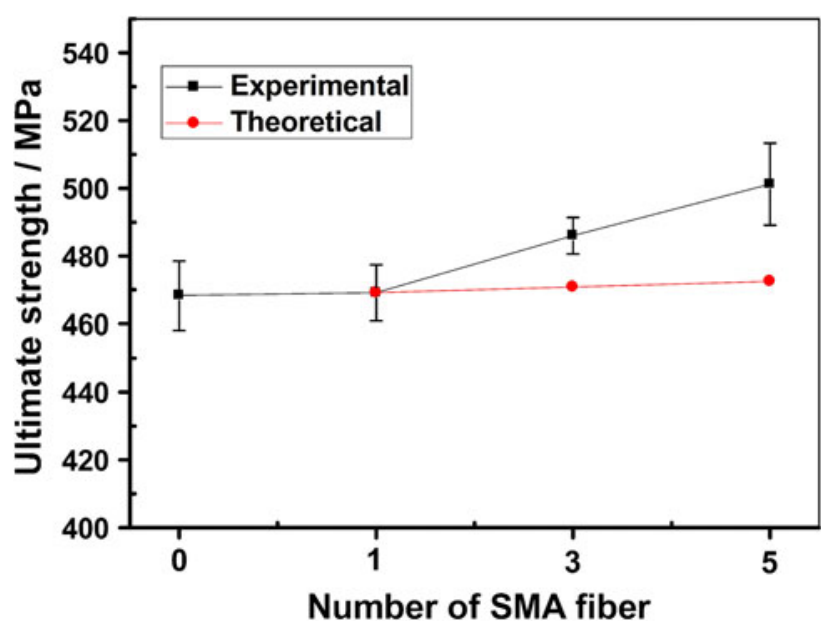

Fig. 8 Comparison of macroscopic ultimate strength between theoretical and experimental results

It has been confirmed that the volume fraction of fiber played an important role in enhancing the overall strength and fracture toughness of composite. The theoretical results of ultimate strength and rupture elongation for SMAs composite are calculated by Eq 8 and 9, as shown in Table 2. Figure 7 shows the comparison of rupture elongation for SMAs composite between theoretical and experimental results. Square dots denote the experimental results, and circle dots denote the theoretical results. It can be found that the overall fracture toughness of composite is obviously improved due to the embedded SMAs fiber, in contrast to glass/resin matrix. It is owing to the SMAs fiber can effectively prevent crack propagation within matrix material. However, the values are slightly decreased from $5.25,5.16$, to $5.1 \%$ with the increase of SMAs fiber number, which tends to the maximum strain of SMAs fiber. Moreover, the experimental results are approximately $13 \%$ higher than theoretical results. Zhang et al. (Ref 9) investigated the mechanical properties of composite filled with SMAs short fiber through flexural testing, and found that the fracture deflection of SMAs filler composite decreased with increasing SMAs filler weight content which was similar to the present results. The comparison of ultimate strength for SMAs composite is shown in Fig. 8. For the single-SMAs-fiber composite, the ultimate strength is only 469.1 MPa which is closer to theoretical results and glass/resin matrix. It indicates that the overall strength of composite is depending on the glass/ resin matrix in the lower volume fraction of SMAs fiber. With the increase of SMAs fiber number, the strength is improved from 468.3 to $469.1 \mathrm{MPa}, 486$ and 501.2 MPa. This is mainly due to the strength of SMAs fiber and was far higher than matrix material at ambient temperature. Additionally, the theoretical result of ultimate strength is slightly lower than experimental. For the five-SMAs-fiber composite, the difference is about $6.07 \%$.

\subsection{Failure Morphology Analysis}

For the fracture failure of fiber-reinforced material, it might be attributed to the matrix cracking, fiber fracture, fiber-matrix interfacial debonding, and their combinations. In this section, the failure mode of SMAs fiber-reinforced composite is evaluated through observing the failure surface using digital HF microscope at ambient temperature. Figure 9 shows the typical failure morphologies. For the unidirectional SMAs fiber-reinforced composite, the longitudinal fracture strain is controlled by the 

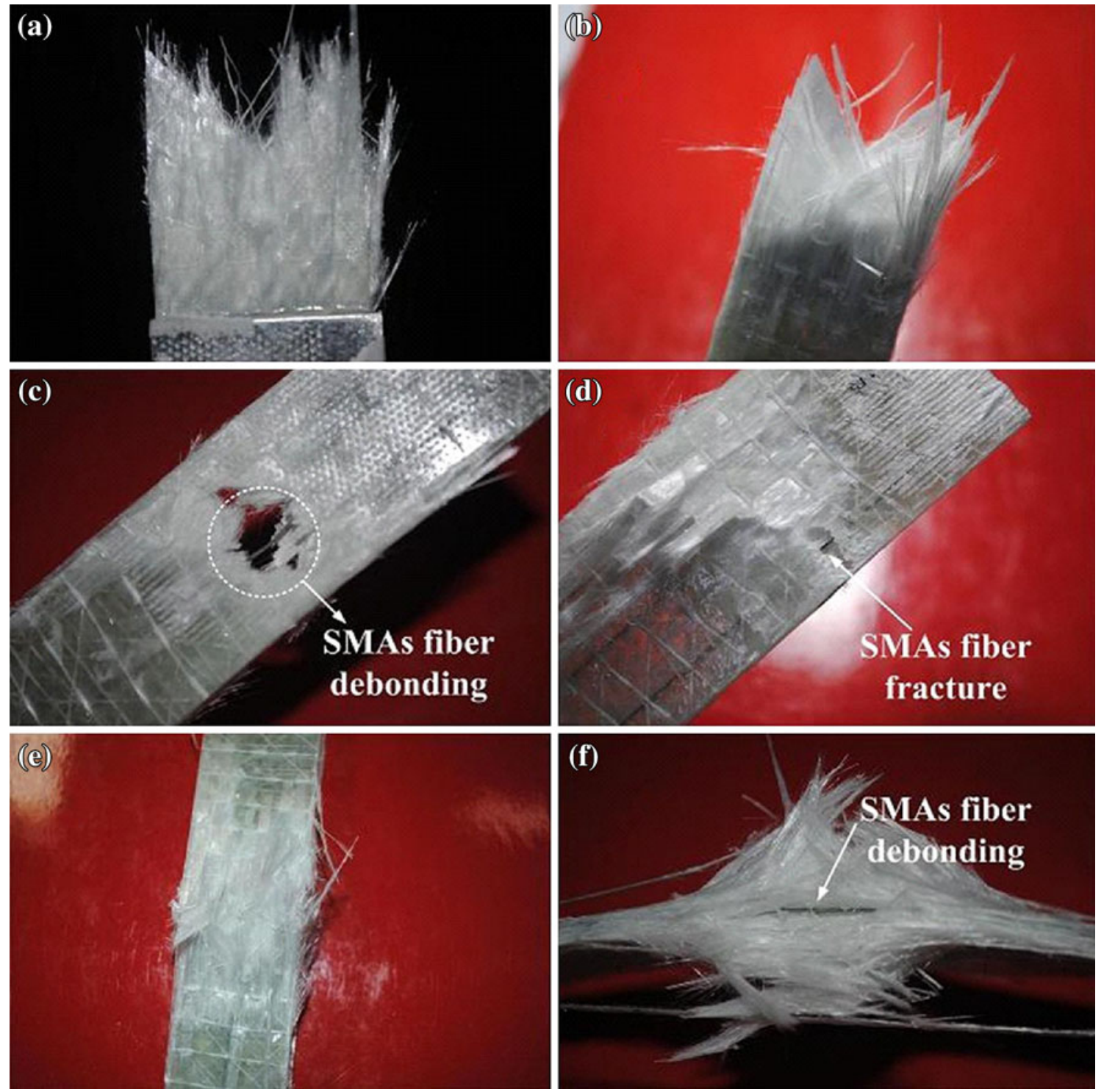

Fig. 9 Failure morphologies of glass/resin matrix and SMAs-reinforced composite

glass/resin matrix and SMAs fiber. As seen in Fig. 9(a) and (b), a $\mathrm{V}$-shape fracture surface is formed at the end of failed glass/resin matrix material, due to the presence of glass cloth layers laying angle of $45^{\circ}$ and $-45^{\circ}$. In Fig. 9(c), a part of SMAs fiber has been pulled out from the glass/resin matrix, and the matrix is damaged. It mainly due to the stiffness or strength of glass/resin matrix and is lower than SMAs fiber. When the longitudinal strain of hybrid composite is increased to ultimate strength, the glass/resin matrix will gradually damage. Meanwhile, the interfacial shear stress will combine with the normal stress of SMAs fiber subject to external load. However, due to the interfacial cohesive between SMAs fiber and glass/resin matrix is weak, thus the interface will gradually debonded, and the SMAs fiber would be pulled out from the composite. Note that it has been confirmed that stress concentration would be occurred near the cross-head around the SMAs fiber due to the non-uniformity of hybrid composite. This leads to SMAs fiber fracture during the process of loading as shown in Fig. 9(d). Additionally, with the increase of the longitudinal strain, the weak interface gradually debonded attributing to the strain incompatibility along the interface, then the glass/resin layers would fracture and the composite lost load capacity as seen in Fig. 9(e) and (f). In summary, the observed results indicate that the macroscopic fracture behavior of SMAs composite would be changed due to the effect of SMAs fiber and weak interface cohesive.

\section{Conclusions}

In present study, the macroscopic mechanical behavior of SMAs fiber-reinforced glass/resin composite subject to uniaxial loading at ambient temperature was investigated through theoretical analysis and experimental tests. Based on the experimental and theoretical analyses, the following observation can be drawn: 
(a) Due to the effect of phase transformation of SMAs fiber, a bilinear mechanical behavior of composite is exhibited. Weak interface is presence between SMAs fiber and matrix due to the discrepancy in material compatibility.

(b) The overall stiffness of composite at the second stage is on average $10 \%$ lower than theoretical results, owing to the influence of weak interfacial cohesive. The rupture elongation of experimental result is approximately $13 \%$ higher than theoretical result.

(c) The macroscopic fracture behavior of SMAs composite is changed due to the effect of SMAs fiber and weak interface cohesive. The local interfacial debonding is the main failure mode.

\section{Acknowledgments}

This project was financially supported by the Chinese National Natural Science Foundation (11272096), Fundamental Research Funds for the Central Universities (HEUCF130216), and Doctoral Program of Higher Education of China (20112304110015). The authors also wish to acknowledge the support of Harbin Engineering University of China, the China Scholarship Council, the University of Sydney (Australia), and the Australian Research Council (DP110104123).

\section{Open Access}

This article is distributed under the terms of the Creative Commons Attribution License which permits any use, distribution, and reproduction in any medium, provided the original author(s) and the source are credited.

\section{References}

1. P. Bassani, C.A. Biff, M. Carnevale, N. Lecis, B. Previtali, and A. Lo Conte, Passive Damping of Slender and Light Structures, Mater. Des., 2013, 45, p 88-95

2. S. Arnaboldi, P. Bassani, C.A. Biffi, A. Tuissi, M. Carnevale, N. Lecis, A. LoConte, and B. Previtali, Simulated and Experimental Damping Properties of a SMA/Fiber Glass Laminated Composite, J. Mater. Eng. Perform., 2011, 20(4-5), p 551-558

3. C.A. Biffi, P. Bassani, A. Tuissi, M. Carnevale, N. Lecis, A. LoConte, and B. Previtali, Numerical and Experimental Characterizations of Damping Properties of SMAs Composite for Vibration Control Systems, J. Mater. Eng. Perform., 2012, 21(12), p 2713-2718

4. H.S. Lei, Z.Q. Wang, L.Y. Tong, B. Zhou, and J. Fu, Experimental and Numerical Investigation on the Macroscopic Mechanical Behaviour of Shape Memory Alloy Hybrid Composite with Weak Interface, Compos. Struct., 2013, 101, p 301-312

5. T.B. Fathollah, T. Farid, and H. Ramin, Characterization of a Shape Memory Alloy Hybrid Composite Plate Subject to Static Loading, Mater. Des., 2011, 32, p 2923-2933

6. J. Raghavan, T. Bartkiewicz, S. Boyko, M. Kupriyanov, N. Rajapakse, and B. Yu, Damping, Tensile, and Impact Properties of Superelastic
Shape Memory Alloy (SMA) Fiber-Reinforced Polymer Composites, Compos. B, 2010, 41, p 214-222

7. G. Zhou and P. Lloyd, Design, Manufacture and Evaluation of bending behaviour of Composite Beams Embedded with SMA Wires, Compos. Sci. Technol., 2009, 69, p 2034-2041

8. J. Aurrekoetxea, J. Zurbitu, I. Ortiz de Mendibil, A. Agirregomezkorta, M. Sánchez-Soto, and M. Sarrionandia, Effect of Superelastic Shape Memory Alloy Wires on the Impact Behavior of Carbon Fiber Reinforced In Situ Polymerized Poly(butylene terephthalate) Composites, Mater. Lett., 2011, 65, p 863-865

9. R.X. Zhang, Q.Q. Ni, T. Natsuki, and M. Iwamoto, Mechanical Properties of Composites Filled with SMA Particles and Short Fibers, Compos. Struct., 2007, 79, p 90-96

10. K.W. Kang and J.K. Kim, Effect of Shape Memory Alloy on Impact Damage Behavior and Residual Properties of Glass/Epoxy Laminates Under Low Temperature, Compos. Struct., 2009, 88, p 455-460

11. S. Pappadà, P. Gren, K. Tatar, T. Gustafson, R. Rametta, E. Rossini, and A. Maffezzoli, Mechanical and Vibration Characteristics of Laminated Composite Plates Embedding Shape Memory Alloy Superelastic Wires, J. Mater. Eng. Perform., 2009, 18(5-6), p 531-537

12. H.S. Lei, Z.Q. Wang, B. Zhou, L.Y. Tong, and X.Q. Wang, Simulation and Analysis of Shape Memory Alloy Fiber Reinforced Composite Based on Cohesive Zone Model, Mater. Des., 2012, 40, p $138-147$

13. M. Tawfik, J.J. Ro, and C. Mei, Thermal Post-buckling and Aeroelastic Behavior of Shape Memory Alloy Reinforced Plates, Smart Mater. Struct., 2002, 11(2), p 297-307

14. P. Lu, F.S. Cui, and M.J. Tan, A Theoretical Model for the Bending of a Laminated Beam with SMA Fiber Embedded Layer, Compos. Struct., 2009, 90, p 458-464

15. S.Y. Kuo, L.C. Shiau, and K.H. Chen, Buckling Analysis of Shape Memory Alloy Reinforced Composite Laminates, Compos. Struct., 2009, 90, p 188-195

16. S. John and M. Hariri, Effect of Shape Memory Alloy Actuation on the Dynamic Response of Polymeric Composite Plates, Compos. A, 2008, 39, p 769-776

17. E.H. Kim, I. Lee, J.H. Roh, J.S. Bae, I.H. Choi, and K.N. Koo, Effects of Shape Memory Alloys on Low Velocity Impact Characteristics of Composite Plate, Compos. Struct., 2011, 93, p 2903-2909

18. L.C. Shiau, S.Y. Kuo, and S.Y. Chang, Free Vibration of Buckled SMA Reinforced Composite Laminates, Compos. Struct., 2011, 93, p 26782684

19. H.K. Cho and J. Rhee, Nonlinear Finite Element Analysis of Shape Memory Alloy (SMA) Wire Reinforced Hybrid Laminate Composite Shells, Int. J. Non-Linear Mech., 2011, 6(47), p 672-678

20. G. Song, B. Kelly, B.N. Agrawal, P.C. Lam, and T.S. Srivatsan, Application of Shape Memory Alloy Wire Actuator for Precision Position Control of a Composite Beam, J. Mater. Eng. Perform., 2000, 9(3), p 330-333

21. K. Tanaka, A Thermomechanical Sketch of Shape Memory Effect: OneDimensional Tensile Behavior, Res. Mech., 1986, 18(2), p 251-263

22. C. Liang and C.A. Rogers, One-Dimensional Thermomechanical Constitutive Relations for Shape Memory Materials, J. Intell. Mater. Syst. Struct., 1990, 1(2), p 207-234

23. J.G. Boyd and D.C. Lagoudas, Thermomechanical Response of Shape Memory Composites, J. Intell. Mater. Syst. Struct., 1994, 5(3), p 333-346

24. L.C. Brinson, One Dimensional Constitutive Behavior of Shape Memory Alloys: Thermomechanical Derivation with Nonconstant Material Functions, J. Intell. Mater. Syst. Struct., 1993, 4(2), p 229-242

25. D.Q. Jiang, L.S. Cui, Y.J. Zheng, X.Q. Zhao, and Y. Li, Constrained Martensitic Transformation in an In Situ Lamella TiNi/NbTi Shape Memory Composite, Mater. Sci. Eng. A, 2009, 515, p 131-133 